\title{
Cross-sectional Thickness at End Ventricular Systole
}

National Cancer Institute

\section{Source}

National Cancer Institute. Cross-sectional Thickness at End Ventricular Systole. NCI

Thesaurus. Code 127596.

The cross-sectional thickness of a tissue measured at end ventricular systole. 